\title{
Optimized Helical Monopole Antennas for Portable VHF Communication Devices
}

\author{
Shifu Zhao, Christophe Fumeaux, Chris Coleman \\ School of Electrical and Electronic Engineering \\ The University of Adelaide \\ Adelaide, South Australia, Australia \\ shifu@eleceng.adelaide.edu.au, cfumeaux@eleceng.adelaide.edu.au, ccoleman@eleceng.adelaide.edu.au
}

\begin{abstract}
The helical monopole antenna has been used extensively as compact antenna for portable VHF communication devices. Conventionally, it has a constant pitch and radius along its body, these being chosen to make the antenna resonant at the frequency of interest. By allowing both radius and pitch to vary along the antenna, it is possible to optimize the antenna in terms of efficiency and bandwidth. The current paper investigates the effect of antenna environment upon such optimizations and, in particular, the situation where the VHF antenna is fed against a small radio casing instead of a perfect ground plane. It is shown that the optimization is little affected by such changes to environment and that the optimized designs are robust. The current paper concentrates on optimizations of pitch since helix radius will need to be constrained in the case of a portable radio.
\end{abstract}

\section{INTRODUCTION}

The helical antenna was first proposed in [1], and has been used extensively in portable communication devices [2]. In particular, it has shown its great value when operating in its normal mode as a shortened resonant omnidirectional antenna for HF and VHF communications. Nevertheless, most helical antennas that are mounted on portable devices are designed using wire wound at fixed pitch and with fixed radius. It has previously been shown in [4] that by continuously varying the pitch along the body of the antenna, a design for normal mode could be optimized in terms of efficiency and bandwidth.

Typically, monopole antennas are designed, simulated, and optimized under the assumptions of ideal environment (an infinite perfect conducting ground plane, and no near-by objects). Such environments, however, do not exist in real world. Consequently, the impact of non-ideal environments upon the robustness of the above optimizations need to be considered and are the subject of this paper. Firstly, we consider the impact when the perfect ground plane is replaced by a planar system of radial wires of finite length. Secondly, and more important from a practical viewpoint, we consider the ground plane replaced by the metal casing of a portable radio. It is shown that the optimized design is robust to such changes in ground plane. Further, we also show that there is a preferred positioning of the antenna upon the case.

For demonstration purpose, a helical antenna with a fixed height of $0.08 \mathrm{~m}$ is designed and optimized for operation at a center frequency of $300 \mathrm{MHz}$. The goal of the design is to maximize the efficiency and bandwidth under perfect matching by continuously varying the pitch. Variations of the
TABLE I

COMPARISON OF UNIFORM AND OPTIMIZED HELICAL ANTENNAS ON AN INFINITE GROUND.

\begin{tabular}{|c|c|c|}
\hline & $\begin{array}{c}\text { Uniform helix on } \\
\text { infinite ground }\end{array}$ & $\begin{array}{c}\text { Optimized helix on } \\
\text { infinite ground }\end{array}$ \\
\hline Efficiency & $93.7 \%$ & $95.1 \%$ \\
\hline Bandwidth & $4.76 \mathrm{MHz}$ & $6.36 \mathrm{MHz}$ \\
\hline & & \\
\hline
\end{tabular}

radius have been considered in [3], but are impractical when considering physical constraints for portable devices. The 0.08 $\mathrm{m}$ total height corresponds to $1 / 12.5$ of the wavelength at 300 $\mathrm{MHz}$, which categorizes the antenna as electrically small. The ultimate goal of the optimization is to find the most appropriate helical configuration mounted at the optimal position on the metallic body of a typical portable communication device (Width $\times$ Length $\times$ Height $=50 \mathrm{~mm} \times 60 \mathrm{~mm} \times 100 \mathrm{~mm}$ ). The improvements to antenna performance are quantified by comparison with the performance of a uniform helix.

\section{Optimized Helical Antennas}

In the current work, the electromagnetic simulator NEC2 [5] is used to model the environment as well as the antenna. A 3-turn resonant uniform helical antenna of $0.08 \mathrm{~m}$ total height with a constant pitch $(P=0.023 \mathrm{~m})$ and $\operatorname{radius}(R=0.015 \mathrm{~m})$ is taken as the reference model for comparison purposes. The goal of the optimization is to find the antenna with maximized efficiency and bandwidth at $300 \mathrm{MHz}$.

\section{A. Infinite Conducting Ground}

First, a 3-turn pitch-varying helix at a fixed overall height of $0.08 \mathrm{~m}$ is optimized on an infinite perfectly conducting ground. The continuous pitch variations are represented and implemented using radial basis functions, as introduced in [4]. For comparison, the uniform helix is also mounted and simulated on the infinite ground plane. The performance and configurations of these two antennas are shown in TABLE I. It can be seen that the optimized helix exhibits a wider bandwidth and greater efficiency. 
TABLE II

COMPARISON OF UNIFORM AND OPTIMIZED HELICAL ANTENNAS ON A FINITE RADIAL WIRE GROUND.

\begin{tabular}{|c|c|c|c|}
\hline & $\begin{array}{c}\text { Uniform helix on } \\
\text { radial wires }\end{array}$ & $\begin{array}{c}\text { Opt. helix on } \\
\text { radial wires }\end{array}$ & $\begin{array}{c}\text { Re-opt. helix with } \\
\text { radial wires }\end{array}$ \\
\hline Efficiency & $94.7 \%$ & $95.5 \%$ & $95.5 \%$ \\
\hline Bandwidth & $5.94 \mathrm{MHz}$ & $7.16 \mathrm{MHz}$ & $7.16 \mathrm{MHz}$ \\
\hline
\end{tabular}

\section{B. Finite Radial Wires Ground}

Second, the impact of finite system of radial wires as a ground is investigated. This ground is composed of 16 radial wires with each wire being $0.25 \mathrm{~m}$ long and $1 \mathrm{~mm}$ thick, as shown in Fig. 1. In order to obtain more realistic results, reoptimization is carried out on the pitching-varying helix with the finite radial wire ground included. The optimal solution indicates very much similar antenna configuration to the one from infinite ground. The performance is consequently very much the same, as shown in TABLE II. It is observed that when 16 radial wires are used, they are effective as a the ground plane, and more importantly, the similarity to the optimized pitch-varying helices for infinite ground proves the robustness of the optimization.

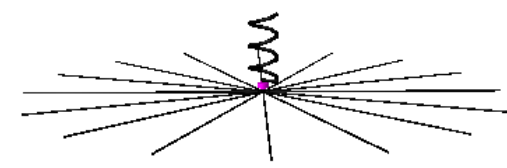

Fig. 1. Uniform helix on finite radial wires

\section{Finite Metal Casing}

Frequently, VHF antennas are used on portable communication devices where a radial wire screen is impractical. Instead, the case of the device is used as the ground for the antenna. Therefore, the performance of a metal casing as a ground is investigated in this paragraph. Again, the uniform and optimal pitch-varying helices obtained for the infinite ground are mounted on the top of a metal case with a dimension of $50 \mathrm{~mm} \times 60 \mathrm{~mm} \times 100 \mathrm{~mm}$. Similarly, reoptimization is performed with the metal casing included to pursue a better optimal solution. It can be seen in TABLE III that, the re-optimization shows a very similar optimal antenna configuration to the one for an infinite plane, but both exhibit a significant degradation in bandwidth. Nevertheless, the similarity in terms of the configuration effectively proves the robustness of the optimization, and provides a guideline in designing pitching varying helix. By altering the pitch distribution along its height with denser wound wires at the top and looser near the bottom, the bandwidth can be increased.

\section{Optimal Loading Position on Metal Casing}

The positioning of the antenna on the case can also be important. In previous paragraph, it has been shown that the antenna performance significantly decreases when the antenna is mounted in the center on top the metal casing. In order to find a better loading position, two other positions on the
TABLE III

COMPARISON OF UNIFORM AND OPTIMIZED HELICAL ANTENNAS ON A Metal CASing.

\begin{tabular}{|c|c|c|c|}
\hline & $\begin{array}{c}\text { Uniform helix on } \\
\text { metal casing }\end{array}$ & $\begin{array}{c}\text { Opt. helix on } \\
\text { metal casing }\end{array}$ & $\begin{array}{c}\text { Re-opt. helix with } \\
\text { metal casing }\end{array}$ \\
\hline Efficiency & $94.1 \%$ & $92.0 \%$ & $92.0 \%$ \\
\hline Bandwidth & $0.75 \mathrm{MHz}$ & $1.14 \mathrm{MHz}$ & $1.14 \mathrm{MHz}$ \\
\hline & & $>$ & \\
& & &
\end{tabular}

TABLE IV

COMPARISON OF OPTIMIZED HELIX AT Different Positions ON THE Metal Casing.

\begin{tabular}{|c|c|c|c|}
\hline & Center & Side & Corner \\
\hline Efficiency & $92.0 \%$ & $94.9 \%$ & $97.0 \%$ \\
\hline Bandwidth & $1.14 \mathrm{MHz}$ & $4.09 \mathrm{MHz}$ & $10.7 \mathrm{MHz}$ \\
\hline Configuration & 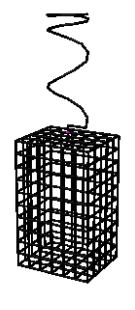 & 膦 & 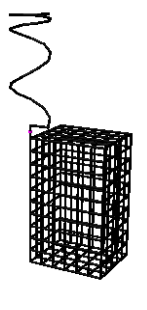 \\
\hline
\end{tabular}

casing, side and corner, were simulated. It was found that altering the loading position can change the antenna performance dramatically, as shown in TABLE IV. By mounting the antenna at the corner on the metal casing, the resulting bandwidth can be greatly improved to $10.7 \mathrm{MHz}$, compared to the center position bandwidth of $1.14 \mathrm{MHz}$.

\section{CONCLUSION}

This paper presents an investigation of normal mode helical monopole antennas for portable VHF communication devices. By allowing pitch to vary along the antenna, it can be optimized with respect to bandwidth. The optimized pitch-varying helices are obtained for different environments including infinite ground, finite radial wires, and a metal casing. Those optimized helices appear to have very similar configurations, and this similarity indicates the robustness of the optimization methodology to differents environments.

\section{REFERENCES}

[1] J. D. Kraus, "Helical beam antenna", Electronics, vol. 20, pp. 109-111, 1947.

[2] K. Fujimoto, "Mobile antenna systems handbook", Artech House Publishers, 2001.

[3] S. Zhao, C. Fumeaux, and C. Coleman, "Optimal helical antenna with continuously varying radius using evolutionary optimizers", Proc. IEEE AP-S Int. Symp. Antennas Propag., pp. 757-760, July 2011.

[4] S. Zhao, C. Fumeaux, and C. Coleman, "Evolutionary optimization of zigzag antennas using gaussian and multiquadric radial basis function", Proc. IEEE Asia Pacific Microwave Conf., pp. 1594-1597, December 2011.

[5] G. Burke, Numerical Electromagnetic Code (Nec2) - Method of Moments, Lawrence Livermore National Laboratory, 1981. 